\title{
The use of neurovascular ultrasound versus digital subtraction angiography in acute ischemic stroke
}

\author{
O uso do ultrassom neurovascular comparado a angiografia digital no AVC isquêmico \\ agudo
}

Marcos C. Lange, Tatiana P. Bruch, Jeff C. Pedrozo, Luana Maranha, Thiago Mamôru Sakae, Robertson Pacheco, Paulo C. Souza, Viviane F. Zétola

\begin{abstract}
Cervical and intracranial arterial evaluation is an important issue for acute ischemic stroke (IS). Objective: Compare the use of the neurovascular ultrasound examination (NVUE) to digital subtraction angiography (DSA) in acute IS patients for diagnosing significant extracranial and intracranial arteriopathy. Method: Nonconsecutive patients with IS or transient ischemic attack admitted within 12 hours of the onset of symptoms were evaluated retrospectively. Standardized NVUE and DSA were done in all patients within the first 120 hours of hospital admission. Results: Twenty-four patients were included in the study. Compared to DSA, the NVUE demonstrated $94.7 \%$ sensitivity and 100\% specificity for identifying symptomatic extracranial and/or intracranial arteriopathy. Conclusion: The standardized NVUE technique demonstrated high sensitivity and specificity compared to DSA for diagnosing arterial abnormalities in acute IS patients.
\end{abstract}

Keywords: transcranial Doppler, ultrasonography, digital substraction angiography, ischemic stroke.

RESUMO

A avaliação cervical e intracraniana é uma etapa importante no AVC isquêmico (AVCi) agudo. Objetivo: Comparar o uso do ultrassom neurovascular (USNV) com técnica padronizada e a angiografia digital (AD) em paciente com AVCi agudo no diagnóstico de doença arterial significativa extra e/ou intracraniana. Método: Pacientes com AVCi e AlT admitidos em até 12 horas do início dos sintomas foram retrospectivamente avaliados. Todos os pacientes foram submetidos a USNV e AD padronizado em até 120 horas da admissão. Resultados: Vinte e quatro pacientes foram incluídos no estudo. Em comparação com a AD, o USNV apresentou sensibilidade de 94,7\% e especificidade de $100 \%$ para o diagnóstico de doença arterial significativa extra e/ou intracraniana. Conclusão: 0 uso de técnica padronizada de USNV demonstrou elevada sensibilidade e especificidade para o diagnóstico de doença arterial significativa extra e intracraniana quando comparado a AD.

Palavras-chave: ultrassom diagnóstico, ultrassom, angiografia, acidente vascular cerebral isquêmico.

The neurovascular ultrasound examination (NVUE), carotid and vertebral duplex (CVD) and transcranial Doppler (TCD), is an important tool for identifying the etiology of ischemic stroke (IS) ${ }^{1}$. Previous studies demonstrated that the compromise of the extracranial and main intracranial arteries could increase the risk of recurrence of IS compared to other stroke mechanisms, even after a transient ischemic attack (TIA) $)^{2,3}$.

The NVUE is a non-invasive and bedside evaluation performed in an acute IS setting as a fast-track procedure, spending less than 15 minutes $^{1}$. In addition, the TCD methodology helps identify microembolism secondary to heart disease and proximal cervical arteries, evaluate recanalization and even increase the effect of thrombolytic therapy ${ }^{4}$.

A more recent technique, transcranial color-coded duplex sonography (TCCS), provides advantages compared to TCD by adding B-mode and color-mode to the spectral Doppler, but few studies have evaluated the NVUE that combines CVD and TCCS during acute IS ${ }^{5,6,7}$. The aim of this study is to compare the use of NVUE (CVD+TCCS) with the gold-standard, digital subtraction angiography (DSA), in diagnosing significant extracranial and intracranial arteriopathy in acute IS patients. 


\section{METHOD}

The authors retrospectively evaluated nonconsecutive patients with IS or TIA admitted to the Emergency Room between February 2010 and July 2011. Inclusion criteria were: (1) fewer than 12 hours between the symptoms onset and hospital admission; (2) confirmed diagnoses of IS or TIA based on clinical, neurological and complementary evaluations; (3) the NVUE (CVD + TCCS) must have been performed within the first 12 hours of hospital admission; (4) the presence of a bilateral temporal acoustic window and a complete extracranial and intracranial evaluation; (5) the DSA exam must have been performed within the first 120 hours of hospital admission. DSA evaluation was considered in the current clinical practice for the patient evaluation as the presence of cortical symptoms and/or non-lacunar lesion and negative electrocardiography and ecocardiography; and (6) non-clinical or technical contraindication for DSA evaluation. The hospital ethics committee authorized this study.

At admission, a neurologist promptly performed an evaluation of all patients and a brain computed tomography (CT) scan exclude other neurological diseases. Patients with indications to thrombolytic therapy were submitted to the local protocol treatment ${ }^{8}$.

All patients underwent a standardized NVUE looking for any extracranial or intracranial abnormalities based on a fast-track neurovascular ultrasound examination (15 min-

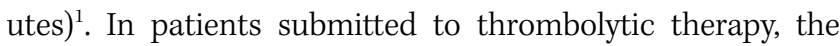
NVUE was performed more than 3 hours after the treatment. The NVUE was performed in bedside with a portable vascular duplex ultrasound (Vivid $\mathrm{E}^{\circledR}$, GE). A 5-12 MHz linear probe was used for the extracranial evaluation, using the B-mode, color-mode and angle-corrected spectral Doppler. The bilateral extracranial evaluation was performed on the common carotid artery (CCA), the external carotid artery (ECA), the internal carotid artery (ICA) and the vertebral artery (VA). For the intracranial evaluation, a $1.5-5 \mathrm{MHz}$ phased array probe was used in B-mode, color-mode and spectral Doppler mode without angle-correction. An experienced neurosonologist (MCL) blind to the clinical data performed the exams and the NVUE results were informed to the clinical team only after the complete investigation.

The bilateral intracranial evaluation was performed on the intracranial internal carotid arteries (ICA), Al and proximal A2 segments of the anterior cerebral arteries (ACAs), $\mathrm{M} 1$ and proximal M2 segments of the middle cerebral arteries (MCAs), P1 and proximal P2 segments of the posterior cerebral arteries (PCAs), V4 segments of vertebral arteries (VAs) and the basilar artery (BA). Intracranial abnormalities were identified when an increased segmental flow velocity associated with retrograde flow, vessel occlusion signals or turbulent flow patterns were observed based on a fast-track neurovascular ultrasound examination ${ }^{1}$. The flow velocity measurements in the intracranial evaluation were not corrected according to the incident angle ${ }^{1,9,10,11}$. The stenosis and occlusion of the extracranial vessels were based on previous studies ${ }^{9,12,13,14}$. All the DSA exams were performed by two experienced neuroradiologists (PCS, RP) blinded to the NVUE results and clinical data. The presence of extracranial stenosis, occlusion higher than $50 \%$, or any grade of intracranial stenosis or occlusion was considered to be a significant abnormality.

The present study evaluated the sensitivity, specificity, negative predictive value (NPV), positive predictive value (PPV) and the accuracy of NVUE compared to DSA (gold-standard) for extracranial and intracranial evaluation. The following variables were analyzed: mean age, gender, the median National Institute of Health Stroke Scale (NIHSS) on admission, the median NIHSS at 24 hours, the median modified Rankin Score (mRS) after seven days and three months, IS or TIA etiology based in a complementary evaluation, symptomatic stroke side, arterial stroke topography, stroke risk factors, time in days between NVUE and DSA evaluation, the concordance between symptomatic NVUE and DSA findings (i) with the extracranial evaluation, (ii) with the intracranial evaluation, and (iii) with the combined extracranial and intracranial evaluation.

Statistical analyses were performed using Epi Info 6.04 software. Statistical significance was assessed by the Chi-square test for categorical variables. Statistical significance was set at $\mathrm{p}<0.05$.

\section{RESULTS}

During the study period, 265 patients were admitted due to IS or TIA, 165 were submitted to NVUE and 81 to DSA. Sixty five (39.3\%) IS or TIA patients underwent both evaluations, NVUE and DSA, for etiological diagnoses. From this group, 41 (63\%) patients were excluded for the following reasons: 25 (38\%) patients were submitted to NVUE 24 hours after the onset of symptoms, eleven (17\%) patients had no temporal window or an incomplete evaluation and five (8\%) underwent the DSA after 120 hours. The demographic findings are presented in the Table 1.

The time period between the NVUE and the DSA was $2 \pm 1$ days, and complications were not observed with any of the diagnostic methods. In 24 patients, 456 arteries were evaluated, including 192 extracranial arteries and 264 intracranial arteries.

For extracranial disease, the CVD identified 14 stenosis (13 in the ICA and one in the VA) compared to 17 stenosis (13 in the ICA and four in the VA) identified by the DSA. Extracranial occlusion was observed in 10 arteries (one in the CCA, eight in the ICA and one in the VA) by the CVD 
Table 1. Demographic characteristics of study patients.

\begin{tabular}{|c|c|c|}
\hline Variable & $\mathrm{N}$ & $\%$ \\
\hline Female & 10 & 41.66 \\
\hline Mean age $\pm P D^{*}$ & $59.25 \pm 14.47$ & - \\
\hline Ischemic stroke & 21 & 87.5 \\
\hline Transient ischemic attack & 3 & 12.5 \\
\hline \multicolumn{3}{|l|}{ Stroke etiology } \\
\hline Large vessel & 16 & 66.66 \\
\hline Cardioembolism & 2 & 8.34 \\
\hline Small vessel & 1 & 4.16 \\
\hline Undetermined & 5 & 20.84 \\
\hline \multicolumn{3}{|l|}{ Stroke side } \\
\hline Left & 13 & 54.16 \\
\hline Right & 11 & 45.84 \\
\hline \multicolumn{3}{|l|}{ Stroke topography } \\
\hline Middle cerebral artery & 21 & 87.5 \\
\hline Anterior cerebral artery & 1 & 4.16 \\
\hline Posterior cerebral artery & 1 & 4.16 \\
\hline Vertebrobasilar circulation & 1 & 4.16 \\
\hline \multicolumn{3}{|l|}{ Stroke risk factors } \\
\hline Arterial hypertension & 15 & 62.5 \\
\hline Diabetes mellitus & 5 & 20.84 \\
\hline Hypercholesterolemia & 4 & 16.66 \\
\hline Smoking habits & 10 & 41.66 \\
\hline Thrombolytic therapy & 8 & 33.33 \\
\hline Median NIHSS ${ }^{+}$admission & 7 & - \\
\hline Median NIHSS ${ }^{\dagger} 24$ hours & 4 & - \\
\hline Median $\mathrm{mRS}^{\ddagger} 7$ days & 2 & - \\
\hline Median $\mathrm{mRS}^{\ddagger} 3$ months & 2 & - \\
\hline
\end{tabular}

$\mathrm{N}$ : Cases number; ${ }^{\star} \mathrm{PD}$ : Pattern deviation; ${ }^{+} \mathrm{NIHSS}$ : National Institute of Health Stroke Scale; ${ }^{\ddagger} \mathrm{mRS}$ : Modified Rankin Score.

compared to 11 (one in the CCA, eight in the ICA and two in the VA) by the DSA. The CVD presented a sensitivity of $85.7 \%$ (95\%CI: 66.4-95.3), a specificity of $100 \%$ (95\%CI: 97.1-99.9), a PPV of $100 \%$ (95\%CI: 82.8-99.6), a NPV of 97.6\% (95\%CI: 93.6-99.2) and an accuracy of 97.9\% (95\%CI: 94.4-99.3), $\mathrm{p}<0.001$.

When only the symptomatic vessel for each patient was considered, the CVD identified nine stenosis (eight in the ICA and one in the VA) compared to nine stenosis (eight in the ICA and one in the VA) identified by the DSA. Extracranial occlusion was observed in six arteries (one in the CCA and five in the ICA) by the CVD compared to six arteries (one in the CCA and five in the ICA) by the DSA. The CVD presented a sensitivity of $100 \%$ (95\%CI: 74.699.3), a specificity of $100 \%$ (95\%CI: 97.3-99.9), a PPV of $100 \%$ (95\%CI: 74.6-99.3), a NPV of $100 \%$ (95\%CI: 97.3-99.9) and an accuracy of 100\% (95\%CI: 97.5-99.9), $\mathrm{p}<0.01$, Table 2 .

In the case of intracranial disease, the TCCS identified three stenosis (all them in the MCA) compared to six stenosis (three in the MCA, two in the PCA and one in the ACA) identified by the DSA. Intracranial occlusion was observed in five arteries by both methods (one in the ACA and four in the MCA). The TCCS presented a sensitivity of $72.7 \%$ (95\%CI: 39.3-92.6), a specificity of $100 \%$ (95\%CI: 98.1-99.9), a PPV of 100\% (95\%CI: 59.7-98.8), a NPV of 98.8\% (95\%CI: 96.3-99.7), and an accuracy of 98.9\% (95\%CI: 96.4-99.7), $\mathrm{p}<0.01$.

When considering only the symptomatic vessel for each patient, the TCCS identified one stenosis in the MCA compared to two stenoses (one in the MCA and one in the PCA) identified by the DSA. Intracranial occlusion was observed in five arteries by both methods (one in the ACA and four in the MCA). The TCCS presented a sensitivity of $85.7 \%$ (95\%CI: 42.0-99.2), a specificity of $100 \%$ (95\%CI: 98.2-99.9), a PPV of $100 \%$ (95\%CI: 51.6-98.4), a NPV of 99.6\% (95\%CI: 97.5-99.9) and an accuracy of 99.6\% (95\%CI: 97.6-99.9), $\mathrm{p}<0.01$, Table 2 .

The symptomatic stenosis and occlusion related to stroke topography was observed in 18 cases by the NVUE compared to 19 patients by the DSA, the only case that was not identified by the NVUE was a distal left P2 PCA stenosis, which probably occurred because this same patient had multiple intracranial stenoses (one distal A2 ACA and both distal P2 PCA segments) that were not suitable to be detected by the TCCS.

When the NVUE (CVD + TCCS) was used to evaluate the symptomatic artery, it demonstrated a sensitivity of $88.5 \%$ (95\%CI: 68.7-97.0), a specificity of $100 \%$ (95\%CI: 98.9-99.9), a PPV of $100 \%$ (95\%CI: 82.2-99.6), a NPV of 99.3\% (95\%CI: 97.8-99.8) and an accuracy of 99.3\% (95\%CI: 97.9-99.8), $\mathrm{p}<0.01$, Table 2 .

\section{DISCUSSION}

The present study demonstrated that in acute IS or TIA patients, NVUE has a high sensitivity and specificity compared to DSA for diagnoses of significant lesions in the extracranial and intracranial symptomatic vessel.

The original fast track NVUE protocol (TCD + CVD), published by Chernyshev et al., demonstrated a $100 \%$ sensitivity and specificity compared to DSA, with all of the symptomatic vessels identified by the NVUE ${ }^{1}$. In the current study, the NVUE (TCCS + CVD) demonstrated $88.5 \%$ sensitivity and $100 \%$ specificity compared to DSA, and the only false negative finding was a distal P2 PCA stenosis that was not visualized by TCCS. This limitation occurred because TCCS is restricted to the proximal segments of the arteries ${ }^{15}$. A similar study that compared TCCS + CVD with DSA in acute IS patients demonstrated $95 \%$ sensitivity and specificity when evaluating only restricted segments of the MCA and PCA arteries 5 .

The importance of the NVUE in acute IS is related to its capacity to identify the site of the clots, predict patient outcome and evaluate vessel recanalization ${ }^{6}$. The identification of tandem occlusion (ICA + MCA) could help in the decision to an interventional therapy because intravenous reperfusion 
Table 2. Carotid and vertebral duplex (CVD), transcranial color-coded duplex sonography (TCCS) and neurovascular ultrasound examination (CVD + TCCS) in the diagnosis of symptomatic extracranial and intracranial arteriopathy compared to digital subtraction angiography.

\begin{tabular}{lccccc}
\hline & $\begin{array}{c}\text { Accuracy } \\
(\%)\end{array}$ & $\begin{array}{c}\text { Sensitivity } \\
(\%)\end{array}$ & $\begin{array}{c}\text { Specificity } \\
(\%)\end{array}$ & $\begin{array}{c}\text { Positive Predictive } \\
\text { Value (\%) }\end{array}$ & $\begin{array}{c}\text { Negative Predictive } \\
\text { Value (\%) }\end{array}$ \\
\hline Symptomatic extracranial arteriopathy by CVD & 100 & 100 & 100 & 100 & 100 \\
Symptomatic intracranial arteriopathy by TCCS & 99.6 & 85.7 & 100 & 100 & 99.6 \\
$\begin{array}{l}\text { Symptomatic extracranial and/or intracranial } \\
\text { arteriopathy by NVUE }\end{array}$ & 99.3 & 88.5 & 100 & 100 & 99.3 \\
\end{tabular}

CVD: Carotid and vertebral duplex; TCCS: Transcranial color-coded duplex sonography; NVUE: Neurovascular ultrasound examination (CVD + TCCS).

treatments demonstrated a low recanalization pattern and a poor outcome ${ }^{16}$.

The advantages of TCCS compared to TCD in the acute setting are the use of M-mode and color-coded evaluation, been more reliably to identify blood flow in a specific intracranial vessel segment with more detailed allocation of vessel pathology and more accurate measurements of the flow velocity. Additionally, TCCS detects the position of the third ventricle and a potential midline shift in the $\mathrm{IS}^{10}$. The use of contrast-enhanced TCCS was better than TCD and TCCS in the acute IS setting ${ }^{7}$. Unfortunately, this echocontrast agent is not available in our country.

In the last decade, ultrasonography has been established as an alternative diagnostic technique for evaluating and screening acute stroke patients. The advantages of ultrasonography over other angiographic methods, such as magnetic resonance angiography or computed tomography angiography, include its real-time results, non-invasiveness, low cost, easy repetition and the possibility of a bedside evaluation. The most significant limitations for its use are technical skills required and the insufficient transtemporal bone windows observed in $17 \%$ of cases in the current study. In a previous study of TCD in a similar population, the insufficient transtemporal bone windows rated $11 \%^{17}$.

In the present study, all false negative by the CVD were observed in the vertebral arteries when considering any stenosis/occlusion, but this disappeared when considering only the symptomatic vessel. This might be related to the stenosis criteria to the vertebral disease and the lower accuracy to find the vertebral artery by ultrasound ${ }^{14}$.
The current study has important limitations. It evaluated a small, highly selective group of patients, a large number of patients was excluded for incomplete evaluation based on the predefined criteria or a delay in the complementary method examination. The present study selected patients admitted to a tertiary hospital within a relatively short period of time after symptoms onset, and this methodology could exclude some patients that arrived later in the hospital. Some patients were submitted to thrombolysis, and this could influence the findings in both techniques. The DSA was done only in patients with clinical indication to perform this methodology, and this could select more critical patients to the analysis. In our hospital, at the moment of the study, patients did not have access to magnetic resonance angiography and computed tomography angiography to be compared with DSA. Another important limitation was the delay between procedures (NVUE and DSA), which could increase the number of false positives found by the NVUE due to acute recanalization, a potential occlusion/stenosis in the NVUE could represent an evanescent stenosis recanalyzed before the DSA. A risk related to this delay might be the false negative result of NVUE, this was observed only in a P2 PCA stenosis that was not visualized by TCCS.

In conclusion, the present study demonstrated that a standardized NVUE evaluation has a high sensitivity and specificity for diagnosing cervical and intracranial arterial abnormalities compared to DSA. The NVUE protocol should be included in all stroke centers to improve stroke diagnosis and to identify different prognosis patterns.

\section{References}

1. Chernyshev OY, Garami Z, Calleja S, Song J, Campbell MS, Noser EA et al. Yield and accuracy of urgent combined carotid/transcranial ultrasound testing in acute cerebral ischemia. Stroke. 2005;36(1):32-7. http://dx.doi.org/10.1161/01.STR.0000150496.27584.e3

2. Purroy F, Montaner J, Molina CA, Delgado P, Ribo M, Alvarez-Sabín $J$. Patterns and predictors of early risk of recurrence after transient ischemic attack with respect to etiologic subtypes. Stroke. 2007;38(12):3225-9. http://dx.doi.org/10.1161/STROKEAHA.107.488833

3. Lovett JK, Coull AJ, Rothwell PM. Early risk of recurrence by subtype of ischemic stroke in population-based incidence studies. Neurology. 2004;62(4):569-73.
4. Zétola VF, Lange MC. The utility of Transcranial Doppler in the acute ischemic stroke. Arq Bras Cardio. 2006;87(6):795-8. http://dx.doi.org/ 10.1590/S0066-782X2006001900018

5. Wada K, Kimura K, Minematsu K, Yasaka M, Uchino M, Yamaguchi T. Combined carotid and transcranial color-coded sonography in acute ischemic stroke. Eur J Ultrasound. 2002;15(3):101-8. http://dx.doi. org/10.1016/S0929-8266(02)00030-7

6. Malferrari G, Bertolino C, Casoni F, Zini A, Sarra VM, Sanguigni S et al. The Eligible study: ultrasound assessment in acute ischemic stroke within 3 hours. Cerebrovasc Dis. 2007;24(5):469-76. http://dx.doi.org/ $10.1159 / 000108922$ 
Goertler M, Kross R, Baeumer M, Jost S, Grote R, Weber S et al. Diagnostic impact and prognostic relevance of early contrastenhanced transcranial color-coded duplex sonography in acute stroke. Stroke. 1998;29(5):955-62. http://dx.doi.org/10.1161/01. STR.29.5.955

8. Lange $M C$, Zétola VF, Parolin MF, Zamproni LN, Fernandes $A F$, Piovesan EJ et al. Curitiba acute ischemic stroke protocol: a university hospital and EMS initiative in a large Brazilian city. Arq Neuropsiquiatr. 2011;69(3):441-5. http://dx.doi.org/10.1590/S0004282X2011000400006

9. Demchuk AM, Burgin WS, Christou I, Felberg RA, Barber PA, Hill MD et al. Thrombolysis in brain ischemia (TIBI) transcranial Doppler flow grades predict clinical severity, early recovery, and mortality in patients treated with intravenous tissue plasminogen activator. Stroke 2001;32(1):89-93. http://dx.doi.org/10.1161/01.STR.32.1.89

10. Nedelmann M, Stolz E, Gerriets T, Baumgartner RW, Malferrari G, Seidel $\mathrm{G}$ et al; TCCS Consensus Group. Consensus recommendations for transcranial color-coded duplex sonography for the assessment of intracranial arteries in clinical trials on acute stroke. Stroke. 2009;40(10):3238-44. http://dx.doi.org/10.1161/STROKEAHA.109.555169

11. Baumgartner RW. Intracranial stenoses and occlusions, and circle of willis collaterals. Handbook on neurovascular ultrasound. Front Neurol Neurosci. 2006;21:117-26. http://dx.doi.org/10.1159/ 000092394
12. Reutern GM, Goertler M-W, Bornstein NM, Del Sette M, Evans DH, Goertler M-W et al. Grading Carotid Stenosis Using Ultrasonic Methods. Stroke. 2012;43(3):916-21. http://dx.doi.org/10.1161/ STROKEAHA.111.636084

13. Grant EG, Benson CB, Moneta GL et al. Carotid artery stenosis: grayscale and Doppler US diagnosis - Society of Radiologists in Ultrasound Consensus Conference. Radiology. 2003;229(2):340-6. http://dx.doi.org/10.1148/radiol.2292030516

14. Büdingen $\mathrm{HC}$, Staudacher T, Büdingen HJ. Ultrasound diagnostic of the vertebrobasilar system. RW Baumgartner. Handbook on neurovascular ultrasound. Front Neurol Neurosci. 2006;21:57-69. http://dx. doi.org/10.1159/000092385

15. Baumgartner RW. Transcranial insonation. Handbook on nNeurovascular ultrasound. Front Neurol Neurosci. 2006;21:105-16. http://dx.doi.org/10.1159/000092393

16. Rubiera M, Ribo M, Delgado-Mederos R, Santamarina E, Delgado P, Montaner $J$ et al. Tandem internal carotid artery/middle cerebral artery occlusion: an independent predictor of poor outcome after systemic thrombolysis. Stroke. 2006;37(9):2301-5. http://dx.doi.org/ 10.1161/01.STR.0000237070.80133.1d

17. Zétola VF, Lange MC, Muzzio JA, Marchioro I, Nóvak EM, Werneck LC. Transcranial Doppler in the neurological practice. Arq Neuropsiquiatr. 2006;64(1):100-3. http://dx.doi.org/10.1590/S0004282X2006000100020 